IP $\rightleftharpoons$ B

\title{
Fragmentação florestal em região semiárida no Nordeste do Brasil
}

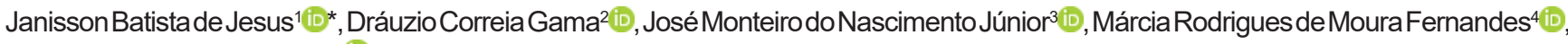 \\ Milton Marques Fernandes 5 \\ ${ }^{1}$ Universidade Federal do Rio Grande do Sul, Campus Vale, Avenida Bento Gonçalves, 9500, CEP 91501-970, Porto Alegre, RS, Brasil \\ ${ }^{2}$ Universidade Estadual do Sudoeste da Bahia, Campus de Vitória da Conquista, Estrada do Bem Querer, Km 04, CEP 45031- 900, Vitória da Conquista, BA, Brasil \\ ${ }^{3}$ Universidade do Estado da Bahia, Campus VIII, Rua do Gongorra, 503, CEP 48600-000, Paulo Afonso, BA, Brasil \\ ${ }^{4}$ Secretaria de Estado do Desenvolvimento Urbano e Sustentabilidade, Rua Vila Cristina, 1051, Bairro 13 de Julho, CEP 49020-150, Aracaju, SE, Brasil \\ 5Universidade Federal de Sergipe, Departamento de Ciências Florestais, Avenida Marechal Rondon, s/n, Jardim Rosa Elze, CEP 49100-000, São Cristóvão, SE, Brasil
}

*Autor correspondente:

janisson-batista-de-jesus@hotmail.com

Termos para indexação:

Remanescentes florestais

Floresta tropical sazonalmente seca

Índices de ecologia da paisagem

Index terms:

Remaining forest

Seasonally dry tropical forest

Indexes of landscape ecology

Histórico do artigo:

Recebido em 01/08/2018

Aprovado em 14/03/2019

Publicado em 30/12/2019

\section{(c) (1) $\Theta \Theta$

BY NC ND

Resumo - Os estudos de ecologia da paisagem a partir de métricas utilizando geoprocessamento e sensoriamento remoto são importantes tecnologias para avaliar as condições dos remanescentes florestais nativos, principalmente em biomas fragmentados e com alta taxa de desmatamento como a Caatinga. Este trabalho objetivou descrever a estrutura da paisagem florestal no município de Ribeira do Pombal, BA, por meio de índices métricos da paisagem. Utilizou-se uma imagem do satélite Landsat-8 OLI para a determinação do uso do solo e dos fragmentos florestais. Para o cálculo das métricas da paisagem, foi utilizado o software Fragstats $4.2^{\circledR}$. Mesmo em uma matriz com alto percentual de pastagens, predominam na paisagem fragmentos de caatinga aberta e densa de tamanhos médio e grande, com grande proximidade e conectividade. O reflorestamento e enriquecimento dos fragmentos muito pequenos da caatinga aberta podem contribuir para serem utilizados como corredores. O grande percentual de fragmentos maiores que 100 ha garante diversidade florística e resiliência da caatinga densa no município de Ribeira do Pombal, BA.

\section{Forest fragmentation in a semiarid region in northeastern Brazil}




\section{Introdução}

O semiárido brasileiro é composto por 1.262 municípios, dos estados do Maranhão, Piauí, Ceará, Rio Grande do Norte, Paraíba, Pernambuco, Alagoas, Sergipe, Bahia e Minas Gerais, com predominância do Bioma Caatinga (Brasil, 2017). A área total da Caatinga corresponde a 826.411,23 $\mathrm{km}^{2}$, sendo que em $2009 \mathrm{em}$ torno de $43,4 \%$ dos remanescentes encontravam-se preservados, com destaque para o estado da Bahia que mais desmatou entre 2008 a 2009 (Brasil, 2011).

Conhecer a situação da distribuição das florestas, e particularmente dos fragmentos remanescentes, é essencial para analisar, manter e garantir a biodiversidade e a conservação dos recursos hídricos (Pereira et al., 2017). Para isto, a Ecologia da Paisagem, por meio de indicadores também conhecidos como métricas da paisagem, possibilita a análise dos fragmentos florestais para que possíveis medidas sejam tomadas (Jesus et al., 2015). A utilização de métricas da paisagem no zoneamento de áreas para conservação da biodiversidade pode indicar qual a melhor técnica de manejo com vista à recuperação e/ou restauração (Juvanhol et al., 2011).

Para Metzger (1999), a estrutura da paisagem pode ser definida por métricas de área, forma e disposição espacial de suas unidades interativas (ecossistemas, unidades de vegetação ou de uso e ocupação do solo). As métricas de área quantificam a composição da paisagem, resultando em informações importantes sobre a dinâmica de populações vegetais e animais (Volotão, 1998). As métricas de forma são responsáveis pela configuração da paisagem. Segundo Forman (1995), diferentes formas de fragmentos podem ser encontradas na paisagem, desde as curvilíneas, compactas ou alongadas até as arredondadas. As métricas de proximidade e isolamento se baseiam na distância entre vizinhos mais próximos e podem ser aplicadas para os três grupos tratados pelo Fragstats, ou seja, fragmento, classe e paisagem (Volotão, 1998).

Os estudos de fragmentação florestal, associados às métricas de paisagem, são desenvolvidos em várias formações florestais, como os observados nos trabalhos de Juvanhol et al. (2011), Mendes et al. (2015), Fernandes \& Fernandes (2017), e Santos et al. (2017). Trabalhos associando a Caatinga à fragmentação florestal são escassos, mostrando que existe uma lacuna no conhecimento da situação atual dos remanescentes desta tipologia vegetal, podendo citar os trabalhos de Silva et al. (2013, 2014), Almeida et al. (2015), Moraes et al. (2015) e Miranda et al. (2018). Isso é decorrente das mudanças na paisagem deste bioma terem sido estudadas de forma genérica, deixando de lado as peculiaridades dos detalhes geográficos sobre as alterações introduzidas pelas práticas agrícolas e pecuárias, que, por sua vez, resultaram no aumento da fragmentação florestal ao longo do tempo (Miranda et al., 2018).

Uma das maneiras de se garantir a existência dos diversos ecossistemas naturais se dá pela implementação de Unidades de Conservação, que foram criadas para proteger e manter os remanescentes de ecossistemas naturais, a fim de reduzir a perda da biodiversidade e garantir sua manutenção em longo prazo (Saito et al., 2016). Contudo, no bioma Caatinga são relativamente raras e pequenas, sendo que as Unidades de uso indireto cobrem uma pequena fração da área original e estão concentradas em algumas das ecorregiões (Velloso et al., 2002). Nas demais regiões, onde não se tem o aparato da proteção legal destas áreas de proteção, a situação da manutenção de florestas fica ainda mais crítica, devido à falta de planejamento territorial dos municípios e ausência de preocupação com a fragmentação florestal da Caatinga.

O município de Ribeira do Pombal, BA, foi ocupado por fazendas de gado desde o período colonial, sendo que a partir de 1970 a atividade agrícola passou a utilizar culturas de ciclo curto, principalmente de feijão e de milho (Cuenca \& Mandarino, 2007). Estas formas de uso da terra promoveram a redução da Caatinga que recobria o município, tornando-a fragmentada ao longo da paisagem. Este trabalho objetivou descrever a estrutura da paisagem florestal neste município, por meio de índices métricos da paisagem.

\section{Material e métodos}

\section{Localização e caracterização da área de estudo}

O município de Ribeira do Pombal situa-se ao nordeste do Estado da Bahia entre as coordenadas 10 $56^{\circ} 18^{\prime \prime} \mathrm{e}$ $10^{\circ} 56^{\prime} 24^{\prime \prime} \mathrm{S}$ e $38^{\circ} 37^{\prime} 48^{\prime \prime}$ e $38^{\circ} 17^{\prime} 42^{\prime \prime} \mathrm{W}$ (Figura 1), com extensão territorial de 762,21 ha. O clima na região é do tipo BSh (Köppen), sendo caracterizado como semiárido, com índice pluviométrico abaixo de $800 \mathrm{~mm}$. ano ${ }^{-1}$ (Alvares et al., 2013). Sua vegetação é caracterizada como arbustivo-arbórea de tipo xerófila, com solos profundoarenosos e dispersos remanescentes da vegetação original do Bioma Caatinga (Pereira Junior, 2007). 


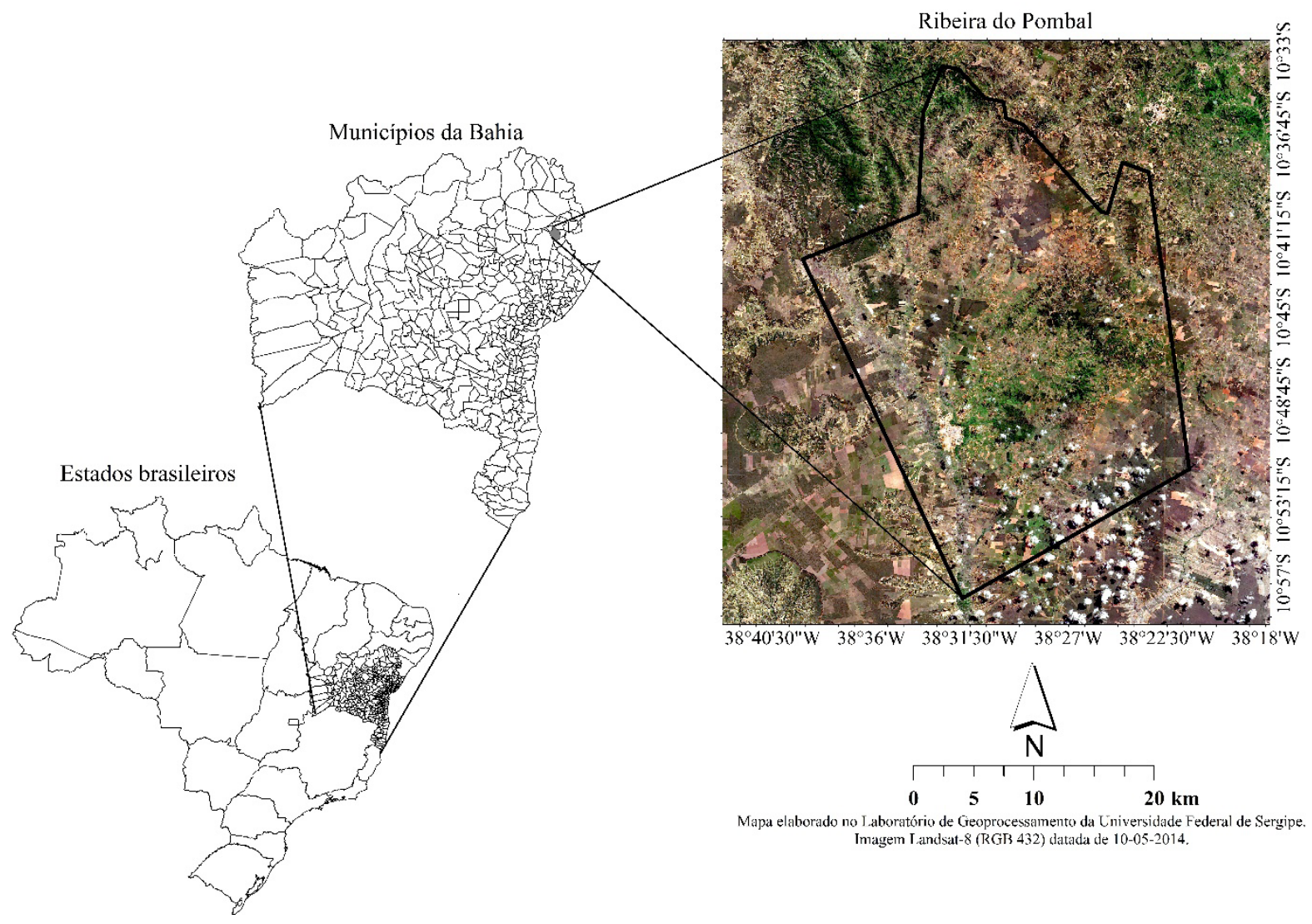

Figura 1. Localização do município de Ribeira do Pombal, Bahia.

Figure 1. Location of the municipality of Ribeira do Pombal, Bahia State, Brazil.

\section{Uso do solo e levantamento dos fragmentos florestais}

As classes de uso e ocupação do solo foram geradas a partir da imagem do Landsat-8 sensor OLI do mês de maio de 2014, por meio da classificação supervisionada por máxima verossimilhança, na equação reduzida do algoritmo (Equação 1), conforme Tso \& Mather (2001).

$$
-\ln \left[\mathrm{P}\left(\frac{\mathrm{x}_{\mathrm{i}}}{\mathrm{w}_{\mathrm{i}}}\right)\right]=\ln \left|\mathrm{C}_{\mathrm{i}}\right|+\left(\mathrm{x}_{\mathrm{i}}-\mu_{\mathrm{i}}\right)^{\mathrm{T}} \cdot \mathrm{C}_{\mathrm{i}}^{-1} \cdot\left(\mathrm{x}_{\mathrm{i}}-\mu_{\mathrm{i}}\right)
$$

Em que: $x$ e $w=$ "eventos"; $P=$ probabilidade de coexistência ou interseção destes eventos; $C=$ matriz de covariância da classe $\mathrm{w}_{\mathrm{i}} ; \mu_{i}=$ vetor médio para a classe $\mathrm{w}_{\mathrm{i}}$; $i=$ determinante da equação.

A classificação automática foi realizada no software Erdas ${ }^{\circledR}$, ferramenta Maximum Likelihood, em que foi possível classificar os seguintes usos e ocupação do solo: solo exposto (áreas urbanas, estradas, áreas degradadas e cultivos agrícolas), pastagem (pastagens bem manejadas, pastagens degradadas e campos sujos) e Caatinga (aberta e densa).

Foram definidas e coletadas 100 amostras de treinamento para cada classe. Para a definição das classes levantadas, obteve-se o conhecimento prévio da área representada na imagem, por meio de visitas em campo nos meses de setembro de 2013 e março de 2014, e utilização da imagem SPOT 5 como referência na identificação das classes de uso e cobertura do solo.

Posteriormente, foi obtido o levantamento dos fragmentos florestais de Caatinga aberta $(40 \% \leq$ recobrimento do solo $<60 \%)$ e densa $(\geq 61 \%$ recobrimento do solo $<80 \%$ ), conforme definição de Chaves et al. (2008).

Com base no levantamento da fragmentação florestal, foi quantificada a área de cada fragmento, de acordo com a tabela de atributos do próprio arquivo da imagem vetorial, tornando possível comparar os tamanhos dos diversos fragmentos florestais encontrados no município 
de Ribeira do Pombal. Os fragmentos na área foram relacionados à classe de tamanho aos quais pertencem, considerando: muito pequenos $(<5 \mathrm{ha})$, pequenos $(5 \leq$ área $<10$ ha), médios ( $10 \leq$ área $<100$ ha $)$ e grandes ( $\geq 100$ ha).

\section{Métricas da paisagem}

Utilizou-se o software Fragstats ${ }^{\circledR} 4.2$ (McGarigal, 2013) para geração dos valores das métricas da paisagem, com base no mapa dos fragmentos florestais. $\mathrm{O}$ arquivo referente ao de fragmentação florestal obtido na etapa anterior no formato raster foi utilizado para o cálculo das métricas da paisagem. As métricas da paisagem selecionadas foram área, densidade, borda, forma, proximidade e conectividade (Tabela 1), para a análise dos elementos da paisagem (McGarigal, 2013).

Realizou-se uma análise das métricas da paisagem por classe de tamanho de fragmento (muito pequeno, pequeno, médio e grande), com a finalidade de se obter valores médios das métricas em todos os fragmentos florestais.

Tabela 1. Métricas utilizadas na quantificação da estrutura da paisagem no município de Ribeira do Pombal, BA.

Table 1. Metrics used to quantify landscape structure in municipality Ribeira of Pombal, Bahia State, Brazil.

\begin{tabular}{|c|c|c|c|}
\hline & Métrica & Sigla e intervalo (unidade) & Grupo \\
\hline $\begin{array}{l}\text { Número de } \\
\text { fragmentos }\end{array}$ & Quanto maior seu valor, mais fragmentada está a cobertura florestal & $\mathrm{NP} \geq 1$ (adimensional) & \multirow{4}{*}{$\begin{array}{l}\text { Área, densidade e } \\
\text { borda }\end{array}$} \\
\hline Área de classe & $\begin{array}{l}\text { Somatório da área de todos os fragmentos de uma determinada classe. } \\
\text { Quanto maior o valor, maior quantidade de área necessária para conservar a } \\
\text { diversidade de espécies }\end{array}$ & $\mathrm{CA}>0$ (ha) & \\
\hline Total de bordas & $\begin{array}{l}\text { Soma de todas as bordas da classe. Quanto maior os valores, maior } \\
\text { influência da borda na classe }\end{array}$ & $\mathrm{TE} \geq 0$ (ha) & \\
\hline $\begin{array}{l}\text { Área média dos } \\
\text { fragmentos }\end{array}$ & $\begin{array}{l}\text { Área média de todos os fragmentos da classe. Quanto maior seu valor, } \\
\text { melhor capacidade de manter maior número de espécies e habitat mais } \\
\text { preservado para a fauna silvestre }\end{array}$ & AREA_MN > 0 (ha) & \\
\hline $\begin{array}{l}\text { Índice de forma } \\
\text { médio }\end{array}$ & $\begin{array}{l}\text { Soma de todos os perímetros dos fragmentos, dividida pelo número de } \\
\text { fragmentos. Quanto maior o valor deste parâmetro, mais alongada é a } \\
\text { forma do fragmento, o que representa maior área de contato com a matriz } \\
\text { antrópica circundante }\end{array}$ & $\begin{array}{l}\text { SHAPE_MN } \geq 1 \\
\text { (adimensional) }\end{array}$ & Forma \\
\hline $\begin{array}{l}\text { Proximidade } \\
\text { média entre } \\
\text { classes }\end{array}$ & $\begin{array}{l}\text { Média aritmética do índice de proximidade dos fragmentos da classe } \\
\text { que é obtido pela soma de cada área dos fragmentos de mesma classe } \\
\text { divididos pela respectiva distância euclidiana borda a borda ao quadrado, } \\
\text { considerando somente os fragmentos dentro do raio de busca. Quanto menor } \\
\text { o valor, maior proximidade entre os fragmentos. }\end{array}$ & $\begin{array}{l}\text { PROX_MN } \geq 0 \\
\text { (adimensional) }\end{array}$ & $\begin{array}{l}\text { Proximidade e } \\
\text { isolamento }\end{array}$ \\
\hline Conectividade & $\begin{array}{l}\text { Quando a coesão é igual a } 1 \text { menos a soma do perímetro do fragmento } \\
\text { dividido pela soma do perímetro do fragmento vezes a raiz quadrada de } \\
\text { sua área para fragmentos correspondentes à mesma classe, dividido por } \\
1 \text { menos } 1 \text { sobre a raiz quadrada da área da paisagem, multiplicado por } \\
100 \text { para converter para percentagem. Quanto maior o valor indica maior } \\
\text { conectividade. }\end{array}$ & $0<$ COHESION $<100(\%)$ & Contágio e dispersão \\
\hline
\end{tabular}

\section{Resultados}

O território de Ribeira do Pombal é representado por aproximadamente $47 \%$ de matriz antrópica, sendo $34 \%$ utilizado para pastagem e $13 \%$ de solo exposto (Figura 2). Os remanescentes florestais ocupam 53\% do território, sendo $31 \%$ coberto por Caatinga aberta e $22 \%$ por Caatinga densa (Figura 2).

Os fragmentos muito pequenos na caatinga aberta apresentam maior número de fragmentos (NP), representando aproximadamente $35 \%$ do NP total (Figura 3). A classe de tamanho pequeno representou $8 \%$ do NP total, a de tamanho médio $30 \%$ e da classe de tamanho grande representou 27\% (Figura 3). Os fragmentos florestais muito pequenos na Caatinga densa representaram aproximadamente $22 \%$ do NP total, os de tamanho pequeno $6 \%$, os de tamanho médio $21 \%$ e os fragmentos grandes representaram o maior percentual com $51 \%$ (Figura 4 ). 
Figura 2. Uso e ocupação do solo do município de Ribeira do Pombal, BA.

Figure 2. Land use and cover in the municipality of Ribeira do Pombal, Bahia State, Brazil.

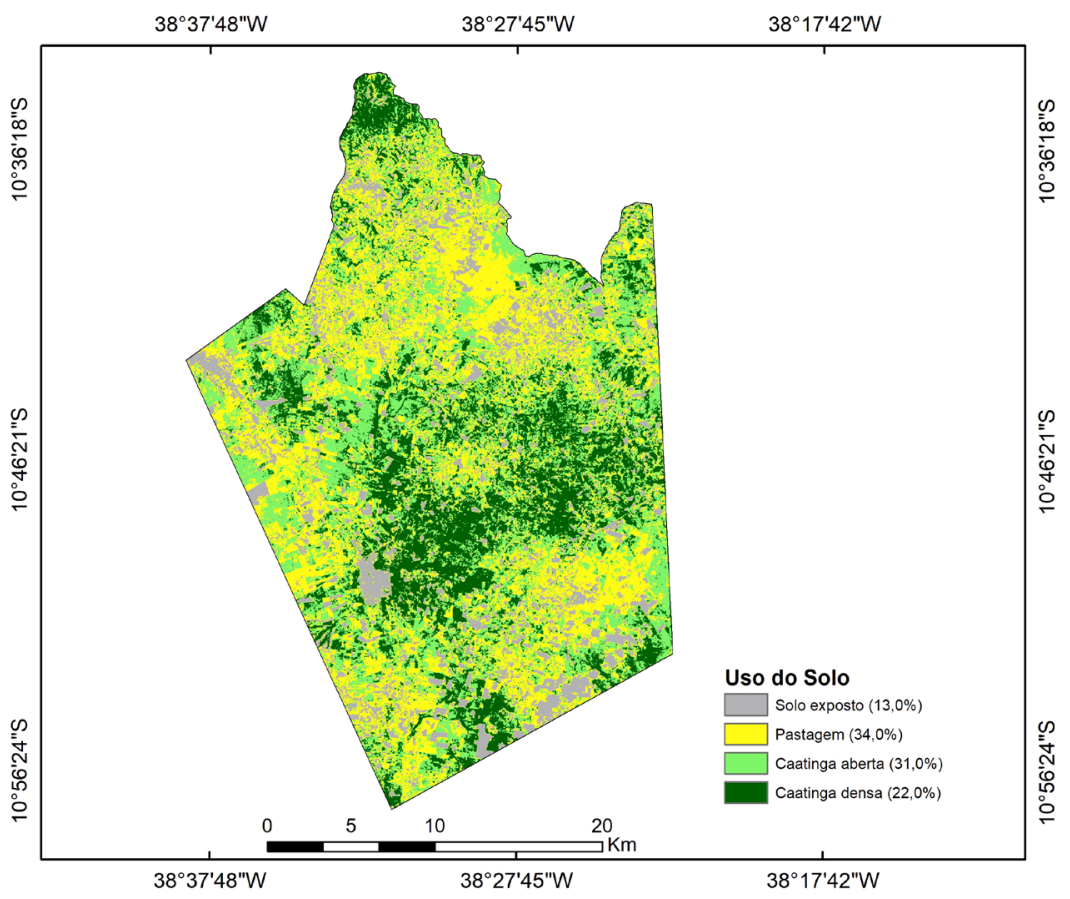

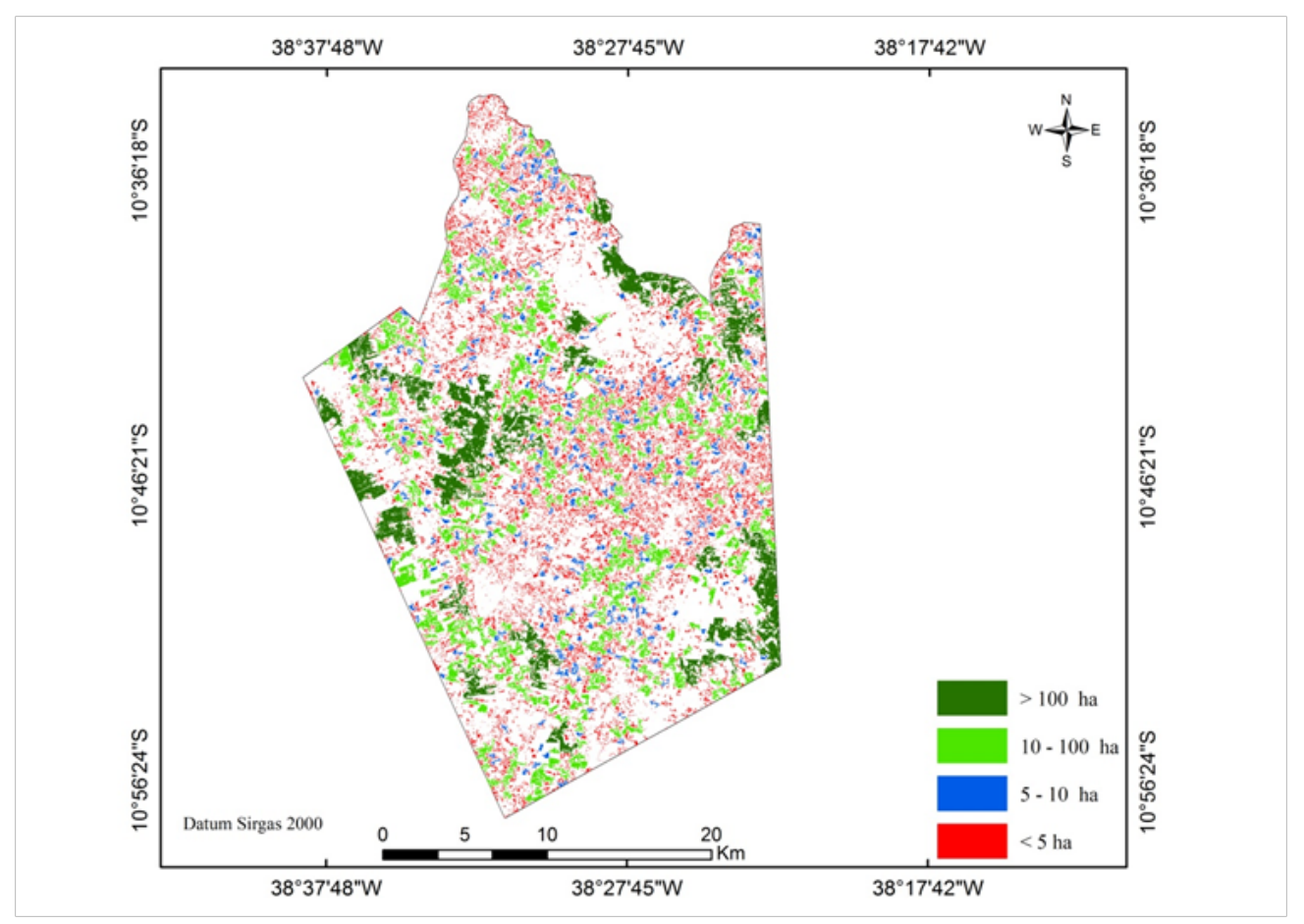

Figura 3. Classes de tamanho dos fragmentos florestais da Caatinga aberta no município de Ribeira do Pombal, BA.

Figure 3. Size classes of the forest fragments of the Open Caatinga in the municipality of Ribeira do Pombal, Bahia State, Brazil. 


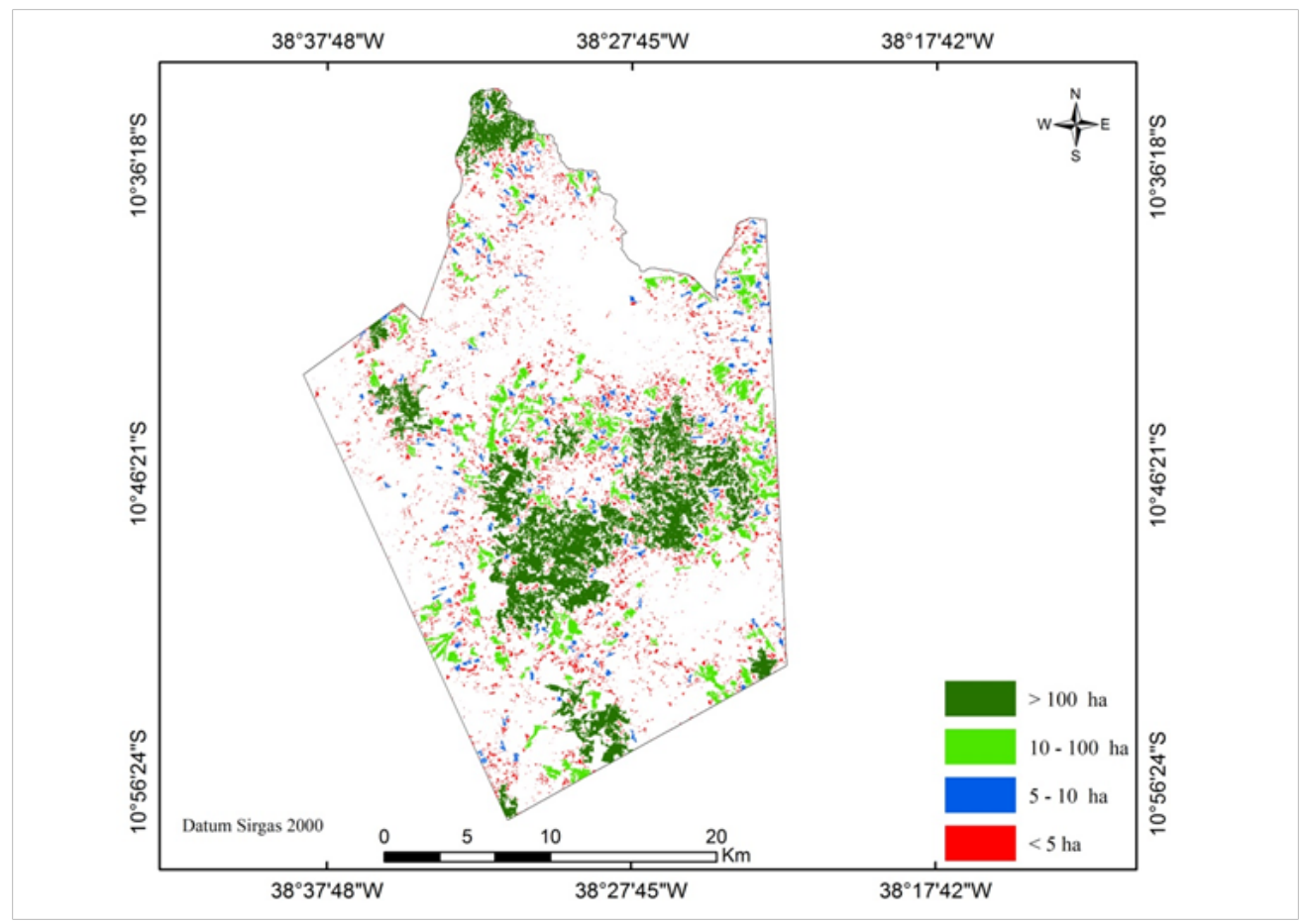

Figura 4. Classes de tamanho dos fragmentos florestais da Caatinga densa no município de Ribeira do Pombal, BA.

Figure 4. Size classes of forest fragments of the dense Caatinga in the municipality of Ribeira do Pombal, Bahia State, Brazil.

O NP foi maior para fragmentos muito pequenos na Caatinga aberta. Na classe fragmentos pequenos foram observados os menores valores de NP e área de classe (CA). Os fragmentos maiores que 10 ha (médios e grandes) na Caatinga aberta apresentam alto valor de NP e CA, associado a uma boa proximidade média (PROX_MN) e conectividade (COHESION) (Tabela 2).

O total de bordas (TE) apresentou maior valor nos fragmentos de tamanho médio e grande na Caatinga aberta. A área média (AREA_MN) dos fragmentos muito pequenos apresentou valor muito mais baixo e os fragmentos grandes muito mais alto que as demais categorias (Tabela 2).

Os fragmentos muito pequenos na Caatinga aberta obtiveram o menor SHAPE_MN. A medida que o tamanho do fragmento aumenta, maior é o valor do SHAPE MN.

O PROX MN entre as diferentes classes de tamanho dos fragmentos na Caatinga aberta estão muito próximas. A métrica COHESION demonstrou que todas as classes de tamanho apresentam uma alta conectividade (Tabela 2).
$\mathrm{Na}$ Caatinga densa os fragmentos florestais da classe de tamanho grande apresentaram maiores NP e CA. Isto demonstra que a paisagem tem um número elevado de fragmentos e com um alto percentual de área na classe de tamanhos grandes (Tabela 3).

OTE dos fragmentos maiores que 100 ha apresentaram o maior TE na Caatinga densa. Destaca-se na classe dos fragmentos muito pequenos um alto valor de TE, apresentando também uma pequena AREA_MN, estando sujeito a maior perda de área central (Tabela 3).

$\mathrm{Na}$ Caatinga densa, os menores valores da métrica SHAPE_MN foram devido aos fragmentos muito pequenos e pequenos, com valores próximos de 1 (Tabela 3).

Os valores da métrica PROX_MN não apresentaram variações nas diferentes classes de tamanho. Em um raio de busca de $100 \mathrm{~m}$, todas as classes de tamanho dos fragmentos de Caatinga densa apresentaram uma grande proximidade. A métrica COHESION demonstrou que independentemente do tamanho do fragmento, todas as classes de tamanho na Caatinga densa apresentaram grande conectividade (Tabela 3 ). 
Tabela 2. Índices de ecologia da paisagem calculados para os fragmentos florestais na Caatinga aberta no município de Ribeira do Pombal, BA.

Table 2. Landscape ecology indices calculated for forest fragments of open Caatinga in the municipality of Ribeira do Pombal, Bahia State, Brazil.

\begin{tabular}{|c|c|c|c|c|}
\hline \multirow[b]{2}{*}{ Índices } & \multicolumn{4}{|c|}{ Classes de tamanho } \\
\hline & $\begin{array}{c}\text { Muito pequeno } \\
\quad(<5 \mathrm{ha})\end{array}$ & $\begin{array}{c}\text { Pequeno } \\
(5 \leq \text { área }<10 \text { ha) }\end{array}$ & $\begin{array}{c}\text { Médio } \\
(10 \leq \text { área }<100 \text { ha) }\end{array}$ & $\begin{array}{c}\text { Grande } \\
(>100 \text { ha })\end{array}$ \\
\hline $\mathrm{NP}$ & 3833 & 928 & 3286 & 2910 \\
\hline $\mathrm{CA}>0$ (ha) & 8095,00 & 1959,00 & 6940,80 & 6147,00 \\
\hline $\mathrm{TE} \geq 0$ (ha) & 1012,82 & 3336,00 & 9065,12 & 6075,66 \\
\hline AREA_MN > 0 (ha) & 0,064 & 7,39 & 28,80 & 279,40 \\
\hline SHAPE_MN $\geq 1(\mathrm{ad})$ & 1,31 & 2,14 & 4,26 & 8,32 \\
\hline PROX_MN $\geq 0$ (ad) & 2392 & 2185 & 2212 & 2301 \\
\hline $0<$ COHESION $<100(\%)$ & 97,04 & 98,45 & 98,73 & 99,03 \\
\hline
\end{tabular}

$\mathrm{NP}=$ número de fragmentos; $\mathrm{CA}=$ área de classe; $\mathrm{TE}$ = total de bordas; AREA_MN = área média dos fragmentos; SHAPE_MN = índice de forma médio; PROX_MN = proximidade média entre classes; COHESION = conectividade.

Tabela 3. Índices de ecologia da paisagem calculados para os fragmentos florestais na Caatinga densa no município de Ribeira do Pombal, BA.

Table 3. Landscape ecology indices calculated for the forest fragments dense Caatinga in the municipality of Ribeira do Pombal, Bahia State, Brazil.

\begin{tabular}{|c|c|c|c|c|}
\hline \multirow[b]{2}{*}{ Índices } & \multicolumn{4}{|c|}{ Classes de tamanho } \\
\hline & $\begin{array}{l}\text { Muito pequeno } \\
\quad(<5 \mathrm{ha})\end{array}$ & $\begin{array}{c}\text { Pequeno } \\
(5 \leq \text { área }<10 \text { ha })\end{array}$ & $\begin{array}{c}\text { Médio } \\
(10 \leq \text { área }<100 \text { ha })\end{array}$ & $\begin{array}{c}\text { Grande } \\
(>100 \text { ha })\end{array}$ \\
\hline NP & 1364 & 386 & 1322 & 3193 \\
\hline $\mathrm{CA}>0$ (ha) & 364,40 & 1034,64 & 3545,10 & 8559,09 \\
\hline $\mathrm{TE} \geq 0$ (ha) & 5004,09 & 900,32 & 4985,85 & 8085,92 \\
\hline AREA_MN > 0 (ha) & 0,05 & 7,13 & 29,05 & 855,90 \\
\hline SHAPE_MN $\geq 1$ (ad) & 1,17 & 2,14 & 3,14 & 9,93 \\
\hline PROX_MN $\geq 0$ (ad) & 8648 & 8437 & 8523 & 8276 \\
\hline $0<$ COHESION $<100(\%)$ & 98,78 & 98,93 & 99,12 & 99,54 \\
\hline
\end{tabular}

$\mathrm{NP}$ = número de fragmentos; $\mathrm{CA}$ = área de classe; TE = total de bordas; AREA_MN = área média dos fragmentos; SHAPE_MN = índice de forma médio; PROX_MN = proximidade média entre classes; $C O H E S I O N=$ conectividade. 


\section{Discussão}

O município de Ribeira do Pombal, BA, apresenta um grande percentual de vegetação de Caatinga (53\%, densa e aberta), superior ao observado por Almeida et al. (2015) que também encontraram um alto percentual, com 45,3\% de Caatinga aberta e densa em Pombal, PB. O percentual observado neste estudo é superior ao definido por Bircol et al. (2018), que define um limiar ecológico global para florestas tropicais entre 30 a $50 \%$ de cobertura florestal para que não haja perda de espécies e alterações da estrutura florestal. No entanto, o município de Ribeira de Pombal tem um percentual alto de pastagens, que se torna uma barreira, reduzindo a capacidade de deslocamento da fauna silvestre. Miranda et al. (2018) analisaram dados ao longo de 38 anos, e observaram que a área relativa da Caatinga na bacia hidrográfica do rio Pontal em Pernambuco, diminuiu de $90 \%$ para $61 \%$, e a fragmentação apresentou uma tendência crescente.

Neste sentido, a natureza da matriz de área florestal deve ser considerada em relação ao deslocamento das espécies da fauna silvestre na paisagem (Moraes et al., 2015), sendo importante a implementação de corredores ecológicos para reduzir efeitos da fragmentação e isolamento dos remanescentes de Caatinga que são circundados por pastagens no município de Ribeira do Pombal, BA.

Os valores de número de fragmentos (NP) na classe de fragmentos muito pequenos na Caatinga aberta foram superiores aos das demais classes, no entanto apresentam uma boa área de classe (CA). Segundo Sartori et al. (2012), esses fragmentos podem servir como corredores para acesso aos fragmentos com maior área nuclear. Silva et al. (2014) constataram que a ação antrópica é um forte modificador da vegetação nativa, ao analisarem a alteração da cobertura da Caatinga em uma bacia hidrográfica do semiárido brasileiro entre os anos de 2000-2010. Os autores verificaram que 65\% da área era composta por uma forte antropização, solo exposto e vegetação rala, com $20 \%$ da unidade de planejamento tendo a vegetação nativa substituída por atividades humanas, sendo que, destes, $12,6 \%$ resultado do uso agrícola e corte raso para obtenção de lenha, e 7,4\% destinados para pastagens. Desta forma, a restauração ecológica das menores classes de tamanho com plantio de espécies nativas ou sistemas agroflorestais é uma maneira para estabelecer a conectividade com fragmentos maiores e melhorar a locomoção da fauna silvestre entre os fragmentos com pouca área no município de Ribeira do Pombal, BA.

Segundo Silva \& Souza (2014), geralmente fragmentos menores, apresentam formas mais circulares e os fragmentos maiores, por possuírem formas recortadas, em função da quantidade de bordas das manchas, possuem valores de SHAPE_MN mais elevados. Os resultados demonstram que o menor tamanho do fragmento neste estudo pode promover maior efeito da matriz circundante. No entanto, segundo Silva et al. (2015), o efeito da matriz antrópica circundante ao fragmento não é o mesmo em toda sua extensão, pois cada espécie (fauna e flora) possui habilidades intrínsecas que variam em função do tipo de matrizes circundantes e outros fatores, como o relevo.

$\mathrm{O}$ alto percentual de fragmentos da Caatinga aberta com área maior que 10 ha permite melhor conservação dos remanescentes deste tipo de vegetação. Embora os fragmentos muito pequenos tenham apresentado maior percentual, e sejam mais susceptíveis ao efeito da matriz antrópica circundante, podem realizar o papel de pontos de ligação (trampolins ecológicos). De acordo com Calegari et al. (2010), os fragmentos menores que 10 ha servem como trampolim ecológico ao longo da paisagem, servindo de refúgio e facilitando o fluxo entre os fragmentos maiores. O papel desses pequenos fragmentos dependem da matriz circundante. $\mathrm{Na}$ matriz dominada por pastagens, deve-se promover a arborização, a restauração e a criação de corredores para melhorar a permeabilidade para a fauna silvestre (Barbosa et al., 2017).

Os grandes fragmentos de Caatinga densa se destacaram na área de estudo em questão (Tabela 3). Esses, quando estão inseridos em uma paisagem com alto percentual de pastagem e solo exposto, funcionam como área-fonte de dispersores, polinizadores e propágulos, gerando condições propícias para a manutenção da biodiversidade local (Calegari et al., 2010).

A Caatinga Aberta apresentou alta quantidade de fragmentos muito pequenos. Esta classe apresentou ainda os menores valores para a métrica SHAPE_MN, reduzindo também a susceptibilidade ao efeito da matriz antrópica que permeia os fragmentos florestais, já que os altos valores indicam que os fragmentos possuem formas alongadas e irregulares (Moraes et al., 2015; Saito et al., 2016). 
Silva et al. (2013), avaliando a fragmentação da Unidade de Conservação Grota do Angico na Caatinga de Sergipe, observaram que a pequena área total e um formato mais alongado não favorecem a manutenção da diversidade de espécies. Outros tipos de vegetação também apresentam elevada fragmentação com a maioria tendo menores áreas (ha), como observado na Mata Atlântica (Saito et al., 2016; Pereira et al., 2017; Santos et al., 2017), na Amazônia (Costa et al., 2015; Massoli Junior et al., 2016), no Cerrado (Goulart et al., 2015) e na restinga (Mendes et al., 2015), ao longo da sub-bacia hidrográfica do rio Comboios.

Esta situação de alta fragmentação dos vários tipos de cobertura florestal chama a atenção para a degradação das áreas de florestas naturais, devendo-se tomar medidas mitigadoras de planejamento e organização territorial, e de interconexão entre os remanescentes ainda existentes, visando à manutenção das funcionalidades, a estabilidade de cada ambiente e a conservação das áreas de maior fragilidade (Muchailh et al., 2010).

\section{Conclusões}

Mesmo em uma matriz com alto percentual de pastagens, predominam na paisagem do município de Ribeira do Pombal, BA fragmentos da Caatinga aberta e densa de tamanho médio e grande, com uma grande proximidade e conectividade.

O reflorestamento e enriquecimento dos fragmentos muito pequenos da Caatinga aberta poderiam contribuir para a formação de corredores ecológicos. O grande percentual de fragmentos maiores que 100 ha garantem a diversidade florística e a resiliência da Caatinga densa em Ribeira do Pombal, BA.

\section{Referências}

Almeida, J. S. et al. Modelagem da dinâmica de uso e ocupação da terra no município de Pombal - PB. Revista Verde de Agroecologia e Desenvolvimento Sustentável, v. 10, n. 1, p. 276-282, 2015. http:// dx.doi.org/10.18378/rvads.v10i1.3923.

Alvares, C. A. et al. Köppen's climate classification map for Brazil. Meteorologische Zeitschrift, v. 22, n. 6, p. 711-728, 2013. http:// dx.doi.org/10.1127/0941-2948/2013/0507.

Barbosa, K. V. C. et al. Use of small Atlantic Forest fragments by birds in Southeast Brazil. Perspectives in Ecology and Conservation, v. 15, p. 42-46, 2017. https://doi.org/10.1016/j.pecon.2016.11.001.
Bircol, G. A. C. et al. Planning by the rules: a fair chance for the environment in a land-use conflict area. Land Use Policy, v. 76, p. 103-112, 2018. https://doi.org/10.1016/j.landusepol.2018.04.038.

Brasil. Ministério da Integração Nacional. Superintendência do Desenvolvimento do Nordeste. Resolução no 107/2017. Estabelece critérios técnicos e científicos para delimitação do Semiárido Brasileiro e procedimentos para revisão de sua abrangência. Recife, 2017. Disponível em: <http://sudene.gov.br/images/2017/arquivos/ Resolucao-107-2017.pdf>. Acesso em: 26 fev. 2019.

Brasil. Ministério do Meio Ambiente. Monitoramento do desmatamento nos biomas brasileiros por satélite: monitoramento do bioma Caatinga 2008-2009. Brasília, DF, 2011. Disponível em: $<$ http://www.mma.gov.br/estruturas/sbf_chm_rbbio/_arquivos/ relatorio_tecnico_caatinga_2008_2009_72.pdf>. Acesso em: 26 fev. 2019.

Calegari, L. et al. Análise da dinâmica de fragmentos florestais no município de Carandaí, MG, para fins de restauração florestal. Revista Árvore, v. 34, n. 5, p. 871-880, 2010. http://dx.doi. org/10.1590/S0100-67622010000500012.

Chaves, I. B. et al. Uma classificação morfo-estrutural para a descrição e avaliação da biomassa da vegetação da caatinga. Caatinga, v. 21, n. 2, p. 201-213, 2008.

Costa, O. B. et al. Análise do processo de fragmentação da floresta nos municípios de Corumbiara e Buritis - RO. Floresta e Ambiente, v. 22, n. 3, p. 334-344, 2015. http://dx.doi.org/10.1590/21798087.044113 .

Cuenca, M. A. G. \& Mandarino, D. C. RRealocação espacial da agricultura no âmbito de microregiões: Bahia, 1990 e 2005. Documentos, Aracaju: Embrapa Tabuleiros Costeiros 2007. 21 p.

Fernandes, M. M. \& Fernandes, M. R. M. Análise espacial da fragmentação florestal da bacia do Rio Ubá - RJ. Ciência Florestal, v. 27, n. 4, p. 1429-1439, 2017. http://dx.doi. org/10.5902/1980509830330.

Forman, R. T. T. Land Mosaics: the ecology of landscape and regions. Cambridge: Cambridge University Press, 1995. 632 p.

Goulart, A. A. et al. Fragmentação da vegetação de Cerrado, entre os anos de 1984 e 2011 no Parque Estadual do Cerrado (Jaguariaíva-PR) e em sua Zona de Amortecimento. Revista Brasileira de Geografia Física, v. 8, n. 3, p. 857-866, 2015.

Jesus, E. N. et al. Estrutura dos fragmentos florestais da Bacia hidrográfica do rio Poxim-SE, como subsídio à restauração ecológica. Revista Árvore, v. 39, n. 3, p. 467-474, 2015. http://dx.doi. org/10.1590/0100-67622015000300007.

Juvanhol, R. S. et al. Análise espacial de fragmentos florestais: caso dos Parques Estaduais de Forno Grande e Pedra Azul, Estado do Espírito Santo.. Floresta e Ambiente, v. 18, n. 4, p. 353-364, 2011. http://dx.doi.org/10.4322/floram.2011.055.

Massoli Junior, E. V. et al. Estimativa da fragmentação florestal na microbacia Sepotubinha, Nova Marilândia - MT, entre os anos de 1990 a 2014. Caminhos de Geografia, v. 17, n. 60, p. 48-60, 2016. https://doi.org/10.14393/RCG176004. 
Mcgarigal, K. Fragstats: Fragstats help: versão 4.2.: computer software program produced by the author at the University of Massachusetts.: Amherst, 2013.

Mendes, N. G. S. et al. Análise espacial da cobertura florestal de restinga da sub-bacia hidrográfica do Rio Comboios, Espírito Santo. Revista Brasileira de Ciências Agrárias, v. 10, n. 2, p. 286-292, 2015. http://dx.doi.org/10.5039/agraria.v10i2a4974.

Metzger, J. P. Estrutura da paisagem e fragmentação: análise bibliográfica. Anais da Academia Brasileira de Ciências, v. 71, n. 3, p. 445-463, 1999.

Miranda, R. Q. et al. Dry forest deforestation dynamics in Brazil's Pontal Basin. Revista Caatinga, v. 31, n. 2, p. 385-395, 2018. http:// dx.doi.org/10.1590/1983-21252018v31n215rc.

Moraes, M. C. P. et al. Análise da paisagem de uma zona de amortecimento como subsídio para o planejamento e gestão de unidades de conservação. Revista Árvore, v. 39, n. 1, p. 1-8, 2015. http://dx.doi.org/10.1590/0100-67622015000100001.

Muchailh, M. C. et al. Metodologia de planejamento de paisagens fragmentadas visando a formação de corredores ecológicos. Revista Floresta, v. 40, n. 1, p. 147-162, 2010.

Pereira Júnior, J.S. Nova delimitação do semiárido brasileiro. Brasília, DF: Biblioteca Digital da Câmara dos Deputados, 2007. $25 \mathrm{p}$.

Pereira, M. P. S. et al. A cobertura florestal em paisagens do Médio Vale do Rio Paraíba do Sul. Floresta e Ambiente, v. 24, p. 1-11, 2017. http://dx.doi.org/10.1590/2179-8087.134115.

Saito, N. S. et al. Geotecnologia e ecologia da paisagem no monitoramento da fragmentação florestal. Floresta e Ambiente, v. 23, n. 2, p. 201-210, 2016. http://dx.doi.org/10.1590/2179-
8087.119814.

Santos, J. F. C. et al. Fragmentação florestal na Mata Atlântica: o caso do município de Paraíba do Sul, RJ, Brasil. Revista Brasileira de Biociências, v. 15, n. 3, p. 151-158, 2017.

Sartori, A. A. C. et al. Combinação linear ponderada na definição de áreas prioritárias à conectividade entre fragmentos florestais em ambiente SIG. Revista Árvore, v. 36, n. 6, p. 1079-1090, 2012. http://dx.doi.org/10.1590/S0100-67622012000600009.

Silva, A. C. et al. Aspectos da ecologia da paisagem e ameaças à biodiversidade em uma unidade de conservação na Caatinga, em Sergipe. Revista Árvore, v. 37, n. 3, p. 479-490, 2013. http://dx.doi. org/10.1590/S0100-67622013000300011.

Silva, M. S. F. \& Souza, R. M. Padrões espaciais de fragmentação florestal na FLONA do Ibura - Sergipe. Mercator, v. 13, n. 3, p. 121-137, 2014. 10.4215/RM2014.1303. 0009.

Silva, R. A. et al. Avaliação da cobertura florestal na paisagem de Mata Atlântica no ano de 2010, na região de Ouro Preto - MG. Cerne, v. 21, n. 2, p. 301-309, 2015. http://dx.doi.org/10.1590/010 47760201521021539.

Silva, R. M. P. et al. Alteração da cobertura vegetal na Sub-Bacia do Rio Espinharas de 2000 a 2010. Revista Brasileira de Engenharia Agrícola e Ambiental, v. 18, n. 2, p. 202-209, 2014. http://dx.doi. org/10.1590/S1415-43662014000200011.

Tso, B. \& Mather, P. M. Classification methods for remotely sensed data. New York: Taylor \& Francis, 2001. 332 p.

Velloso, A. L. et al. (Ed). Ecorregiões: propostas para o bioma Caatinga. Recife: Associação Plantas do Nordeste; Instituto de Conservação Ambiental, 2002. 76 p.

Volotão, C. F. S. Trabalho de análise espacial: métricas do Fragstats. São José dos Campos: INPE 1998. 